auspicious one, the Society had but a short life and came to an end within a year. Halliwell-or HalliwellPhillipps as he was called in later life-was a great writer on Shakespeare. He arranged and described the Stratford-on-Avon archives and initiated the movement for the purchase of the site of New Place, Shakespeare's residence there.

\section{Whales Stranded in Scotland}

ScotLaND is favoured by the number of whales and whale carcases which are deposited upon its shores, and although this accident of position involves the expenditure of dealing with unsavoury nuisances, it has its scientific value. Accordingly a memorandum has been addressed to Scottish medical officers of health, sanitary officers, and the like, by the British Museum (Natural History), requesting the co-operation of these local officers in recording the stranding of whales, porpoises, and dolphins. Whenever a whale is stranded upon the British coast, a telegram, followed in due course by a detailed report, is sent to the Museum by the receiver of wreck or coastguard, and the Museum telegraphs to the sender to let him know whether the whole or any part of the whale is wanted, either for purposes of identification or for preservation. In this way much valuable information has been gathered in recent years regarding the cetaceans frequenting British waters and their seasonal movements; and the present memorandum aims atextending the scheme of notification. It states that as a rule a few days' delay does not affect the condition of a stranded whale, that a small whale killed by stranding can lie on a beach for as much as three weeks without giving rise to any serious nuisance and without entailing the slightest risk of infection, and that carcases moored in the water will keep quite well for as long as seven weeks. It is also pointed out that in this matter the British Museum is working in co-operation with the Royal Scottish Museum, Edinburgh, and that an eventual sharing of the specimens between the two museums has been arranged.

\section{Protection of the Grey Seal}

THE Fishery Board for Scotland has issued a notice directing the attention of fishermen and others to the provisions of the Grey Seals Protection Act of 1932. By that enactment a close time exists, between Sept. 1 and Dec. 1 inclusive, for the taking of grey seals (Halichorus grypus). Any person taking, killing, or wounding any grey seal within the above-mentioned close season is liable on summary conviction to a penalty not exceeding $£ 5$, and any owner, master, charterer, or hirer of a boat, using or permitting his boat to be used for the purpose of taking, killing, or wounding grey seals during the close season, is liable on conviction to a penalty not exceeding $£ 10$.

\section{Animal Groups in Philadelphia Museum}

REgaRDING our comment about the incongruous grouping of small mammals in certain cases in the Museum of the Academy of Natural Sciences of Philadelphia (July 16, 1932, p. 90), Mr. Leigh Mitchell Hodges, public relations director of the Academy, writes to say that the sole purpose of the cases in question was to bring together the outstanding ex- amples of the small mammals common to Pennsylvania and New Jersey. No effort was made to exhibit them in their natural surroundings, the grouping being simply a convenient aggregation primarily for the education of school children. Nevertheless, the introduc. tion of a certain amount of ' environment ' might suggest to children the definite association in Nature of species not usually found together, and this possibility is what we had in mind. In the Museum as a whole, as is well known, great progress has been made in the development of habitat groups, the large cases illustrating lions, Kodiak brown bears, Stone's sheep, and Rocky Mountain goats being particularly fine examples of such exhibits. During the present year, groups of musk-oxen and whistling swans have been constructed, and the programme for the future includes cases of the giant sable antelope, African animals at a water-hole, and the giant panda of Tibet.

\section{Hancock Museum, Newcastle-upon-Tyne}

THE Council of the Natural History Society of Northumberland, Durham, and Newcastle-upon-Tyne has decided to issue an occasional museum bulletin, with the view of keeping members and associates in closer touch with the activities of the Society and the Museum. The first number of the Bulletin contains short paragraphs directing attention to the summer field meetings of the Society, the Museum wild-flower exhibit, and the new arrangement of the Abel Chapman collection of big game trophies and birds of prey. A curious addition to the collections is a hybrid between an English pheasant cock and a white Wyandotte hen, much larger and heavier than an ordinary pheasant, but very pheasant-like in carriage and shape and in the plumage of head, neck, back, and sides. Legs and feet follow the domestic fowl pattern, and the right leg bears a short spur. The bird tasted more of fowl than of pheasant. It is matter for regret that the increase of goldfinches in parts of Northumberland and Durham has attracted the professional bird-catcher, so that the beautiful birds are again threatened with extinction. A strong appeal is made for an increase in membership, so that the good work of this century-old Society may be continued unabated.

\section{B.D.H. Book of Analytical Reagents}

A SECOND, revised, and enlarged edition of "The B.D.H. Book of A.R. Standards" has been issued (price 2s. 6d. net; postage 6d. extra) by the British Drug Houses, Ltd., Graham St., City Road, London, N.1. Fifty new substances have been added to the 158 chemicals in the first edition, and the limit. ing values of the various tests have been stated at the head of each section in the form of a table which represents the maximum permissible limits for the various impurities. We may remind readers of NATuRE that the letters A.R. (replacing the unsatisfactory description " Chemically Pure", or C.P., an unattainable ideal) denote analytical reagents of controlled and specified purity, and users of such reagents will thus be able, by means of this monograph, to judge what impurities may possibly be present and in what amounts. It is clear that, with improvement in analytical chemistry, some of the specifica.

$$
\text { No. 3281, VoL. 130] }
$$

